\title{
Öğretmen Adaylarının Örtük Program Kaynaklı Stres Algılarının Örgüt Kültürü Açısından Değerlendirilmesi
}

\author{
Remzi Yıldırım a,b, Metin Aşçı ${ }^{c}$
}

\section{Özet}

$\mathrm{Bu}$ araştırma ile öğretmen adaylarının örtük programdan kaynaklanan stres algılarını belirlemek ve bu durumu örgüt kültürü açısından değerlendirmek amaçlanmıştır. Araştırmada nicel araştırma yöntemlerinden genel tarama modeli kullanılarak durum saptaması yapılmıştır. Veriler, "Örtük Programdan Kaynaklanan Stres Algılarının Belirlenmesi Ölçeği" adlı veri toplama aracılı̆̆ı ile 364 öğretmen adayından toplanmıştır. Veriler normal dağılım göstermediği için nonparametrik analizler kullanılmıştır.Katılımcıların ölçekten aldıkları puan ortalamalarında cinsiyet ve GANO puanları değişkenine göre anlamlı bir farkın olup olmadığına bakılırken "Mann Whitney U Analizi", bölüm değişkenine göre anlamlı bir farkın olup olmadığına bakılırken "Krusskal Wallis Analizi" uygulanmıştır. Cinsiyet değişkenine göre kadın öğretmen adayları lehine anlamlı fark bulunmuş, GANO puanına göre ise anlamlı fark bulunmamıştır. Bölüm değişkenine göre öğrenci boyutunda anlamlı fark bulunmamış, öğretmen boyutunda anlamlı fark bulunmuştur. Farkın olduğu gruplar "Dunn Analizi" ile belirlenmiştir. Araştırmada elde edilen bulgular ile örtük programın daha önceden kestirilemeyen olumsuz çıktılarının yol aç九tğı stres algıları, örgüt kültürü bazında değerlendirilmiştir.
Anahtar Kelimeler

Öğretmen Adayları

Örtük Program Stres Algisi

Örgüt Kültürü

Makale Hakkında

Geliş Tarihi: 24.10.2019

Kabul Tarihi: 13.03.2020

Doi: 10.18026/cbayarsos.637905

\section{Evaluation of Pre-Service Teachers' Hidden Curriculum Stress Perceptions According to Organizational Culture}

Abstract

It is aimed to determine pre-service teachers' hidden curriculum stress perception and to evaluate it in organizational culture. General survey model was used. The data was collected from 364 pre-service teachers with "The scale for identification of primary school students' perception of stress led by hidden curriculum". Normal distribution wasn't observed. "Mann Whitney U Analysis" was used for looking significant difference according to gender and GANO scores and "Krusskal Wallis Analysis" for department variable. According to gender there was a significant difference and no significant difference in GANO scores. There wasn't significant difference in student dimension, significant difference was found in teacher dimension in department variable. The significant differences between groups were determined by "Dunn Analysis". With the findings stress perceptions caused by the unpredictable negative outcomes of the hidden curriculum have been evaluated on the basis of organizational culture.
Keywords

Pre-service Teachers

Hidden Curriculum

Stress Perception

Organizational Culture

About Article

Received: 24.10 .2019

Accepted: 13.03 .2020

Doi: 10.18026/cbayarsos.637905

a İletişim Yazarı: yildirimremzi@hotmail.com

b Öğretim Görevlisi Dr., Manisa Celal Bayar Üniversitesi Eğitim Fakültesi 45900 Demirci Manisa, ORCID numarası: 0000-0002-6918-5416

c Doktor Öğretim Üyesi, Manisa Celal Bayar Üniversitesi Eğitim Fakültesi 45900 Demirci Manisa, ORCID numarası:0000-0002-2526-0437 


\section{Giriş}

Dünyayla benzer biçimde Türkiye'de de öğretmen yetiştirme görevi eğitim fakültelerinin işlevi olarak görülmektedir. Bu işlev doğrultusunda mesleğin gerekliliklerini yerine getirme yeterliliğine sahip öğretmenlerin mesleğe hazırlanması eğitim fakültelerinde uygulanan eğitim / öğretim programlarının kalitesi ile doğru orantı göstermektedir. İstenen becerilerle donatılmış bireyleri yetiştirmek için belirlenmiş amaç ve konulardan oluşan bu programlara resmi program adı da verilmektedir. Ancak resmi program dışında, öğretmen adaylarının edindikleri bilgi, beceri ve tutumlarına yön veren yazılı olmayan bir başka program türü de mevcuttur. Örtük program olarak adlandırılan bu program; resmi programın ötesinde, eğitim sürecinde oluşan bilgi, fikir ve uygulamalar ile öğretmen adaylarının eriştikleri nitelikleri kapsamaktadır (Yüksel, 2002). Başka bir deyişle, örtük (gizil) programın resmi programda olmayan her şeyi içerdiği fakat resmi programın çıktıları üzerinde önemli etkisi olduğu da söylenebilir (Ahola, 2000; Bergenhenegouwen, 1987; Rennet-Ariev, 2008).

Öğretmen yetiştirme alanında örtük programın teorik temellerinin atıldığı çalışmada Ginsburg ve Clift (1990) öğretmen yetiştirme sürecinde örtük programla ilgili çalışmaları sistemli bir biçimde incelemiş ve sonuç olarak öğretmen yetiştirmeye yönelik uygulamalarda örtük programı üç ana kategoride toplamıştır.

a. Öğretmenlik Mesleği: Örtük mesajlar aracilı̆̆ı ile öğretmenlik mesleğinin statüsü ve gücü öğrencilere anlatılır.

b. Pedagoji: Resmi ve örtük biçimde öğretmen adaylarına pedagoji alanından bazı öğretiler sunulur. Örneğin çağımızda aktif yöntemlerin etkililiği ve gerekliliği anlatılır ama uygulamada karşılaşılabilecek bazı sorunların varlığı mesaj olarak da verilir.

c. Toplum ve Toplumla İlişkiler: Öğretmen eğitimi içerisinde yer alan örtük program toplumlardaki eşitsizlik ve ayrımcılı̆̆ kurumların ve sosyal ilişkilerin olumlu yanlarına yönelik mesajlar verir.

Örtük program aracılı̆̆ı ile öğrencilere / öğretmen adaylarına kurumların (fakültelerin) beklentileri ile uyumlu bilgi, tutum ve düşüncelerin kazandırılması amaçlansa da bazı durumlarda istendik davranışların yanı sıra amaçlanmayan davranışların da süreç içinde öğretmen adayları tarafından kazanıldığı bilinmektedir. Amaç dışı kazanılan bu davranışların örgüt kültürü açısından olumsuz etkiler doğurduğu açıktır. Başka bir deyişle örtük programın okul kültürünü de ifade ettiği düşüncesi de söylenebilir (Yangın ve Dindar, 2010).

Örgüt (okul) kültürü içten gelen bir bütünleşme ve dışarıya karşı uyum sürecinde örgüt üyelerine yol gösterecek varsayım ve inançlar olup, örgütün geneline yayılmış bir yapıdadır (Schein, 1992). Örgüt (okul) kültürü yazılı kuralların yanı sıra ortamda gerçekleşen yazılı olmayan yaşantıların tümünden de etkilenmektedir. Öğretmen adaylarının fakülteleri içinde karşılaştıkları daha önceden planlanmamış yaşantılar sonucu olumsuz sayılabilecek bazı davranış biçimlerini kazanmaları bir problem olarak kabul edilmektedir. Özellikle istem dışı kazanılan bu davranışlar öğretmen adaylarında meslekleri ile ilgili stres kaynağ oluşturmakta ve bazı durumlarla nasıl başa çıkabilecekleri konusunda soru işaretleri meydana getirmektedir. Öğretmen adayları tarafından alınan eğitim onları bir meslek mensubu yapmaktan öte; düşünen, üreten, amaç sahibi olan bireyler haline getirmeyi 
hedeflemektedir (Savcı ve Aysan, 2014). Bu hedeflerin başarılmasında öğretmen yetiştirme sürecinde öğretmen adaylarının algıladığı stresin azaltılması önemlidir. Ülke kaynaklarından eğitim için ayrılan para, zaman ve diğer kaynaklar göz önüne alındı̆̆ında örtük program kaynaklı olumsuz etkilerin belirlenip öğretmen adaylarının algıladıkları stres düzeyinin aşağıya çekilmesi önem arz etmektedir. Özellikle gelecek yıllarda formal eğitim kurumları içinde yer alacak öğretmen adaylarının görev yapacakları okullara, mesleklerine ilişkin yüksek stres ve kaygı düzeyi ile gitmeleri arzu edilen bir durum değildir. Örgüt kültürünün bu durum karşısında olumlu katkı sağlamasının mümkün olduğu ve öğretmen adaylarının kendilerini gelecekte daha güçlü hissetmelerine olanak verecek biçimde örgüt kültürünü oluşturan unsurlar ve işlevler olduğu söylenebilir.

Schein (1988) örgüt kültürünü oluşturan unsurları; değerler, varsayımlar, normlar, semboller ve öyküler, inançlar, kahramanlar olarak sıralamıştır. Norman (1991) ise örgüt kültürünün işlevlerini şöyle açıklamıştır;
a. Örgütü biçimlendiren bir araçtır.
b. Sosyalleşme sürecidir.
c. Örgütle ilgili sorunların çözüm anahtarıdır.
d. Moral ve güdülenme sağlayıcıdır.
e. Örgütsel iklimin, etkinlik ve verimliliğin oluşumunda kilit roldedir.
f. Örgütsel değişimde araç ve anahtardır.
g. Örgütte tutarlılık ve mükemmellik belirtisidir.

Her eğitim kurumunda var olduğu bilinen örtük programın örgüt kültürü, örgüt kültürünün unsurları ve işlevleri ile yakın ilişkisi söz konusudur. Örgüt kültürünün arzu edilen biçimde olduğu durumlarda örtük program aracılığı ile öğretmen adaylarına yönelik pek çok olumlu kazanımın sunulabilmesi mümkün olacaktır.

Alan yazın incelendiğinde örtük programla ilgili yapılan çalışmaların genelde ilköğretim ve ortaöğretim kademesinde yoğunlaştığ1 görülmektedir. Eğitim fakültelerinin örtük programı üzerine yapılan çalışmalar sayıca istenen düzeyde olmayıp, sonuçlarının örgüt kültürü içinde ele alınıp yorumlanmasına yönelik bir çalışmaya rastlanılmamıştır. Ahola (2000), Astin (1993), Bergenhenegouwen (1987), Ginsburg ve Clift (1990), Margolis (2001), Margolis ve Romero (1998), Nelsen (1981), Snyder (1971) yükseköğretim düzeyinde örtük program konusunda çalışmalar yapan araştırmacılar olarak karşımıza çıkmakla birlikte; Adler (2006), Korthagen ve Kessels (1999), Rennet-Ariev (2008) öğretmen adaylarına yönelik örtük program çalışmaları yürütmüş araştırmacılar olarak belirgin biçimde tespit edilmiştir. Bu manada örtük programın örgüt kültürü ile ilişkili bir biçimde ele alınma ihtiyacı araştırmacıları bu yönde çalışma yapmaya yöneltmiştir. Bu çalışmada araştırmacılar öğretmen adaylarının örtük program kaynaklı stres algılarını belirlemeye ve örgüt kültürünün işlevleri bakımından değerlendirmeye yöneltmiştir.

Çalışma ile eğitim fakültelerinde öğrenim görmekte olan öğretmen adaylarının örtük program kaynaklı stres algılarının ortaya konması ve bu durumun örgüt kültürü açısından değerlendirilip tartışılması amaçlanmıştır. Ayrıca örtük program kaynaklı olumsuz stres algılarının etkisini azaltacak biçimde; daha verimli öğrenme çıtıları elde etmeye yönelik ve örgüt kültürü üzerinde olumlu etki sağlamaya yönelik önerilerin geliştirilmesi hedeflenmiştir. 
$\mathrm{Bu}$ çalışmanın problem durumu şu şekilde ortaya konmuştur:

“Öğretmen adayları üzerindeki örtük program kaynaklı stres algılarının örgüt kültürü açısından değerlendirilmesi."

Problem durumuna yönelik belirlenen alt problemler ise aşağıda sıralandığı biçimdedir:

1. Öğretmen adaylarının örtük problemden kaynaklanan stres algılarına yönelik betimsel istatistikler nedir?

2. Öğretmen adaylarının cinsiyetine göre örtük programdan kaynaklanan stres algıları anlamlı farklılık göstermekte midir?

3. Öğretmen adaylarının bölümüne göre örtük programdan kaynaklanan stres algıları anlamlı farklılık göstermekte midir?

4. Öğretmen adaylarının genel ağırlıklı not ortalamalarına (GANO) göre örtük programdan kaynaklanan stres algıları anlamlı farklılık göstermekte midir?

Bu çalışmada araştırma kapsamında ele alınan alt problemler yoluyla ulaşılan bulgular örgüt kültürünün işlevleri çerçevesinde değerlendirilmiş ve bu yönde öneriler geliştirilmeye çalışılmıştır.

\section{Yöntem}

Bu bölümde; araştırma modeli, evren ve örneklem, veri toplama araçları, verilerin toplanması ve analizi biçimindeki başlıklar aracılığı ile çalışmanın yöntemi açıklanmıştır.

\section{Araştırma Modeli}

$\mathrm{Bu}$ çalışma nicel araştırma yöntemlerine göre yürütülmüştür. Nicel araştırma yöntemlerinde bağımsız ve nesnel bir biçimde gözlem, ölçüm ve analiz yapılabilmekte olup (Büyüköztürk, Çakmak, Akgün, Karadeniz ve Demirel, 2013), tarama ve deneme olarak iki ana model vardır. Tarama modelleri mevcut durumu olduğu gibi gösterebilmekte (Şimşek, 2012) ve durumu var olduğu şekliyle betimleyebilmektedir (Karasar, 2012). Bu çalışmada genel tarama modeli kullanılmış olup, durum saptaması yapılmıştır.

\section{Evren ve Örneklem}

Araştırmalar evrenin tamamı veya evreni temsil eden örneklem üzerinden yürütülmektedir (Karasar, 2012). Bu kapsamda araştırma evrenini oluşturan MCBÜ Eğitim Fakültesinde 2018 - 2019 eğitim öğretim yılı bahar döneminde kayıtlı olan 1906 öğretmen adayından Şahin'in (2012) belirttiği biçimde \%95 güven düzeyi ve \%5 hata payı gözetilerek 364 öğretmen adayına önce bölüm ve ardından cinsiyet bazında tabakalı örneklem yoluyla Tablo 1'de gösterildiği biçimde ulaşılmıştır. 
Tablo 1. Çalışmanın Bölüm ve Cinsiyet Bazında Evren ve Örneklem Durumu

\begin{tabular}{lcccccc}
\hline Bölüm & Kadın & Erkek & Toplam & Kadın & Erkek & Toplam \\
\hline Fen Bilgisi Öğretmenliği & 207 & 92 & 299 & 40 & 18 & 58 \\
İlk. Matematik Öğretmenliği & 136 & 56 & 192 & 26 & 11 & 37 \\
Rehberlik ve Psikolojik Danış. & 195 & 102 & 297 & 36 & 19 & 55 \\
Sınıf Öğretmenliği & 266 & 120 & 386 & 51 & 23 & 74 \\
Sosyal Bilgiler Öğretmenliği & 220 & 120 & 340 & 42 & 23 & 65 \\
Türkçe Öğretmenliği & 227 & 165 & 392 & 43 & 32 & 75 \\
Toplam & 1251 & 655 & 1906 & 238 & 126 & 364 \\
\end{tabular}

\section{Veri Toplama Araçları}

Veriler, Yıldırım ve Gürol (2017) tarafından geliştirilmiş olan “Örtük Programdan Kaynaklanan Stres Algılarının Belirlenmesi Ölçeği" adlı veri toplama aracıyla toplanmıştır. İlgili ölçek 5'li Likert tipinde hazırlanmış bir ölçme aracı olup, ölçeğin Cronbach Alpha biçimindeki güvenirlik kat sayısı .957 olarak hesaplanmıştır ve ölçek toplam varyansın \%44,523'ünü açıklamıştır. Ölçeğin açımlayıcı faktör analizi 510 öğrencinin, doğrulayıcı faktör analizi 469 öğrencinin katılımıyla yapılmıştır. Ölçekte; öğrenci, öğretmen ve yönetici ve okulun imkânları biçiminde üç boyut bulunmakta olup, güvenirlik katsayıları sırasıyla .949, .895, .857 biçiminde elde edilmiştir.

\section{Verilerin Toplanması ve Analizi}

Çalışmada verilerin toplanmasına ilgili ölçme aracının kullanım izninin alınmasıyla başlanmış, ardından uygulama formuna bağımsız değişken olarak belirlenen öğrencilerin cinsiyet, bölüm ve GANO puanları ile öğretmen ve öğrenci boyutuna yönelik maddeler yerleştirilmiştir. Uygulama formuna yönelik uygulama izinlerinin de alınmasıyla katılımcıların rızaları ve gönüllülükleri esas alınarak veriler toplanmıştır. Toplamda 391 öğretmen adayına ulaşılmış, toplanan verilerin 27 tanesi geçersiz olduğu için değerlendirme dışı tutulmuş, geriye kalan 364 veri değerlendirmeye alınmıştır. Öğretmen adaylarının katıldığı bu çalışmada veriler rastgele örneklem yöntemiyle toplanmıştır.

Daha sonra analizler yapılırken önce elde edilen veriler anlamlılık düzeyi $(p=.05)$ dikkate alınarak normal dağılım testlerine tabi tutulmuştur. Her bir boyut ve veri setinin tamamında hem Kolmogorov-Smirnov testi hem de Shapiro-Wilk testi sonuçlarına göre verilerin normal dağılım göstermediği $(\mathrm{p}<.05)$ gözlemlenmiştir. Verilerin betimsel istatistikleri analiz edilirken minimum, maksimum, aritmetik ortalama $(\bar{x})$ ve standart sapma (ss) değerleri kullanılmıştır. Verilerin normal dağılım göstermemesinden ötürü cinsiyet ve GANO bazında anlamlı fark olup olmadığı "Mann Whitney U Analizi”, bölüm bazında anlamlı fark olup 
olmadığı "Krusskal Wallis Analizi" aracılığ1 ile incelenmiştir. Verilerin çözümlenmesi esnasında bölüm bazında öğretmen boyutuna ve ölçeğin tamamına ilişkin fark görülmüş ve farkın yönü "Dunn Analizi” ile belirlenmiştir. Elde edilen veriler çalışmanın tartışma / sonuç ve öneri bölümünde Norman'ın (1991) kuramsal olarak belirlemiş olduğu örgüt kültürünün işlevleri temelinde değerlendirilmiştir.

\section{Bulgular}

Bu bölümde çalışmada belirlenmiş olan alt problemlere göre elde edilen bulgular sırasıyla verilmiş bulunmaktadır.

Çalışmanın Birinci Alt Problemine Yönelik Elde Edilen Bulgular

Çalışmanın birinci alt problemi “Öğretmen adaylarının örtük problemden kaynaklanan stres algılarına yönelik betimsel istatistikler nedir?" biçimindedir ve ölçekte yer alan alt boyutlara ve ölçeğin tamamına yönelik veri seti aracılığı ile elde edilen bulgular Tablo 2' de gösterildiği biçimdedir.

Tablo 2. Öğretmen Adaylarının Örtük Program Kaynaklı Stres AlgılarıBetimsel İstatistikleri

\begin{tabular}{lccccr}
\hline Boyut & $\mathbf{n}$ & Minimum & Maksimum & $\overline{\mathbf{x}}$ & ss \\
\hline Öğrenci & 364 & 16.00 & 75.00 & 44.98 & 12.19 \\
Öğretmen & 364 & 18.00 & 90.00 & 71.16 & 18.15 \\
Tamamı & 364 & 37.00 & 165.00 & 116.14 & 26.94 \\
& & & & & \\
\hline
\end{tabular}

Öğretmen adaylarının örtük program kaynaklı stres algılarına yönelik aritmetik ortalama puanları öğrenci boyutu için 44.98 (bazen), öğretmen boyutu için 71.16 (sık sık), tamamı için 116.14 (sık sık) şeklinde çıkmıştır.

Öğrenci boyutunda 3.38 (bazen) aritmetik ortalama puanla "Sınıf arkadaşlarımın eşyalarımı izinsiz kullanmaları" biçimindeki madde en yüksek değeri, 2.35 (nadiren) aritmetik ortalama puanla "Sınıftaki arkadaşlarımdan bazılarının kötü alışkanlıklara sahip olması (sigara, içki, okuldan kaçma)" biçimindeki madde en düşük değeri almıştır.

Öğretmen boyutunda 4.24 (her zaman) aritmetik ortalama puanla “Öğretim elemanının bazı öğrencileri kayırıp eşit davranmaması" biçimindeki madde en yüksek değeri, 3.55 (sık sık) aritmetik ortalama puanla "Öğretim elemanının beni sınıfın önünde uyarması" biçimindeki madde en düşük değeri almıştır.

Çalışmanın İkinci Alt Problemine Yönelik Elde Edilen Bulgular

Çalışmanın ikinci alt problemi “Öğretmen adaylarının cinsiyetine göre örtük programdan kaynaklanan stres algıları anlamlı farklılık göstermekte midir?" biçiminde olup, ölçekte yer alan alt boyutlara ve ölçeğin tamamına yönelik veri seti aracilığı ile elde edilen bulgular Tablo 3'de gösterildiği biçimdedir. 
Tablo 3. Öğretmen Adaylarının Cinsiyetine Göre Örtük Programdan Kaynaklanan Stres Algıları Arasında Anlamlı Farklılı̆̆ Gösteren Mann Whitney U Analizi

\begin{tabular}{lrrrrrr}
\hline Boyut & Cinsiyet & $\mathbf{n}$ & Sıra ortalaması & Sıra toplamı & $\mathbf{U}$ & $\mathbf{p}$ \\
\hline \multirow{2}{*}{ Ögrenci } & Kadın & 238 & 200.24 & 47657.00 & 10772.00 & .000 \\
& Erkek & 126 & 148.99 & 18773.00 & & \\
\multirow{2}{*}{ Öğretmen } & Kadın & 238 & 198.27 & 47188.50 & 11240.50 & .000 \\
& Erkek & 126 & 152,71 & 19241.50 & & \\
Tamamı & Kadın & 238 & 201.18 & 47880.00 & & \\
& Erkek & 126 & 147.22 & 18550.00 & & \\
& & & & & & \\
\hline
\end{tabular}

Öğretmen adaylarının örtük program kaynaklı stres algılarına yönelik her bir boyut ve tamamı için alınan puanlar kadın ve erkek cinsiyetine bağlı olarak kadın öğretmen adayları lehine anlamlı farklılık göstermektedir $(\mathrm{p}=.00)$.

Çalışmanın Üçüncü Alt Problemine Yönelik Elde Edilen Bulgular

Çalışmanın üçüncü alt problemi "Öğretmen adaylarının bölümüne göre örtük programdan kaynaklanan stres algıları anlamlı farklılık göstermekte midir?" biçiminde olup, öğrenim görülen bölümler kapsamında elde edilen veri seti aracılığı ile ulaşılan bulgular öğrenci boyutuna yönelik Tablo 4'te, öğretmen boyutuna yönelik Tablo 5'te ve tamamına yönelik Tablo 7'de gösterildiği biçimdedir.

Tablo 4. Öğretmen Adaylarının Bölümüne Göre Örtük Programdan Kaynaklanan Stres Algıları Arasında Öğrenci Boyutunda Anlamlı Farklılığı Gösteren Kruskall Wallis Analizi

\begin{tabular}{|c|c|c|c|c|c|}
\hline Bölüm & $\mathbf{n}$ & Sira Ortalaması & $\mathbf{X}^{2}$ & $s d$ & $\mathbf{p}$ \\
\hline Fen Bilgisi Öğretmenliği & 58 & 192.03 & & & \\
\hline İlköğretim Matematik Öğret. & 37 & 151.30 & & & \\
\hline Rehberlik ve Psikolojik Danışmanlık & 55 & 178.34 & & & \\
\hline Sınıf Öğretmenliği & 74 & 187.10 & 4.281 & 5 & .510 \\
\hline Sosyal Bilgiler Öğretmenliği & 65 & 189.88 & & & \\
\hline Türkçe Öğretmenliği & 75 & 182.63 & & & \\
\hline Toplam & 364 & & & & \\
\hline
\end{tabular}

Tablo 4'e göre öğretmen adaylarının örtük program kaynaklı stres algıları kapsamında ölçme aracının öğrenci boyutundan aldıkları puanlar eğitim aldıkları bölümlere bağlı olarak anlamlı farklılık göstermemektedir $\left(X^{2}=4.281, s d=5, \mathrm{p}=.510\right)$. 
Tablo 5. Öğretmen Adaylarının Bölümüne Göre Örtük Programdan Kaynaklanan Stres Algıları Arasında Öğretmen Boyutunda Anlamlı Farklılığı Gösteren Kruskall Wallis Analizi

\begin{tabular}{|c|c|c|c|c|c|}
\hline Bölüm & $\mathbf{n}$ & Sira Ortalaması & $\mathbf{X}^{2}$ & $s d$ & $\mathbf{p}$ \\
\hline Fen Bilgisi Öğretmenliği & 58 & 181,09 & \multirow{7}{*}{19.628} & \multirow{7}{*}{5} & \multirow{7}{*}{.001} \\
\hline İlköğretim Mat. Öğretmenliği & 37 & 133,69 & & & \\
\hline Rehberlik ve Psikolojik Danışmanlık & 55 & 169,17 & & & \\
\hline Sınıf Öğretmenliği & 74 & 211,35 & & & \\
\hline Sosyal Bilgiler Öğret. & 65 & 164,54 & & & \\
\hline Türkçe Öğretmenliği & 75 & 204,54 & & & \\
\hline Toplam & 364 & & & & \\
\hline
\end{tabular}

Tablo 5'e göre öğretmen adaylarının örtük program kaynaklı stres algıları kapsamında ölçme aracının öğretmen boyutundan aldıkları puanlar eğitim aldıkları bölümlere bağlı olarak anlamlı farklılık göstermektedir $\left(X^{2}=19.628, s d=5, \mathrm{p}=.001\right)$.

Farklılı̆̆ın hangi gruplar arasında olduğunu belirlemek amaciyla post - hoc analizlerin non parametriği olarak kullanılan Dunn analizi uygulanmış ve öğrenci boyutuna göre farkın olduğu gruplar $(\mathrm{p}<.05)$ Tablo 6 aracilığ1 ile gösterilmiştir.

Tablo 6. Öğretmen Adaylarının Örtük Program Kaynaklı Stres Algılarının Bölümde Öğretmen Boyutuna Göre Farkın Olduğu Grupların Çoklu Karşılaştırıldığı Dunn Analizi

\begin{tabular}{lr}
\hline Bölüm & $\mathbf{p}$ \\
\hline Matematik - Sosyal & .154 \\
Matematik - RPD & .113 \\
Matematik - Fen & .032 \\
Matematik - Türkçe & .001 \\
Matematik - Sınıf & .000 \\
Sosyal - RPD & .810 \\
Sosyal - Fen & .383 \\
Sosyal - Türkçe & .025 \\
Sosyal - Sınıf & .009 \\
RPD - Fen & .547 \\
RPD - Türkçe & .058 \\
RPD - Sinıf & .024 \\
Fen - Türkçe & .202 \\
Fen - Sınıf & .101 \\
Türkçe - Sınıf & .693 \\
\hline
\end{tabular}


Tablo 5 incelendiğinde “İlköğretim Matematik Öğretmenliği, Sosyal Bilgiler Öğretmenliği ve Rehberlik ve Psikolojik Danışmanlık" bölümü öğretmen adaylarının örtük programdan kaynaklanan stres algılarına yönelik madde sıra ortalamaları öğretmen boyutunda diğer bölümlere göre daha düşük düzeyde kalmıştır. Tablo $6^{\prime}$ da görüldüğü üzere bu bölümlerin karşılaştırıldıkları diğer bölümlerden $\mathrm{p}<.05$ düzeyinde anlamlı farklılık oluşmuştur.

Tablo 7. Öğretmen Adayları Bölümüne Göre Örtük Program Kaynaklı Stres Algıları

Arasında Verilerin Tamamına Göre Anlamlı Farklılığı Gösteren Kruskall Wallis Analizi

\begin{tabular}{lrrrrr}
\hline Bölüm & $\mathbf{n}$ & Sıra Ortalaması & $\mathbf{X}^{\mathbf{2}}$ & $\boldsymbol{s} \boldsymbol{d}$ & $\mathbf{p}$ \\
\hline Fen Bilgisi Öğretmenliği & 58 & 186,03 & & & \\
İlköğretim Mat. Öğretmenliği & 37 & 142,86 & & \\
Rehberlik ve Psikolojik Danışmanlık & 55 & 169,46 & & \\
Sını Öğretmenliği & 74 & 203,45 & 11.800 & 5 & .038 \\
Sosyal Bilgiler Öğret. & 65 & 170,20 & & \\
Türkçe Öğretmenliği & 75 & 198,88 & & \\
Toplam & 364 & & & \\
\hline
\end{tabular}

Tablo 7'ye göre öğretmen adaylarının örtük program kaynaklı stres algıları kapsamında ölçme aracının tamamından aldıkları puanlar eğitim aldıkları bölümlere bağlı olarak anlamlı farkl11ık göstermektedir $\left(X^{2}=11.800, s d=5, p=.038\right)$.

Farklılı̆̆ın hangi gruplar arasında olduğunu belirlemek amaciyla post - hoc analizlerin non parametriği olarak kullanılan Dunn analizi uygulanmış ve farkın olduğu gruplar $(p<.05)$ Tablo 8 aracılığı ile gösterilmiştir.

Tablo 8. Öğretmen Adaylarının Örtük Program Stres Algılarının Bölümde Bazında Verilerin Tamamına Göre Farkın Olduğu Grupların Çoklu Karşılaştırıldığı Dunn Analizi

\begin{tabular}{lr}
\hline Bölüm & p \\
\hline Matematik - RPD & .234 \\
Matematik - Sosyal & .207 \\
Matematik - Fen & .051 \\
Matematik - Türkçe & .008 \\
Matematik - Sınıf & .004 \\
RPD - Sosyal & .970 \\
RPD - Fen & .403 \\
RPD - Türkçe & .115 \\
RPD - Sinıf & .070 \\
Sosyal - Fen & .405 \\
Sosyal - Türkçe & .108 \\
Sosyal - Sınıf & .063 \\
Fen - Türkçe & .485 \\
Fen - Sınıf & .345 \\
Türkçe - Sınıf & .791 \\
\hline
\end{tabular}


Tablo 7 incelendiğinde "İlköğretim Matematik Ö̆ğretmenliği” bölümü öğretmen adaylarının örtük programdan kaynaklanan stres algılarına yönelik madde sıra ortalamaları ölçeğin tamamında diğer bölümlere göre daha düşük düzeyde kalmıştır. Tablo 8'de görüldüğü üzere bu bölümün karşılaştırıldığı Türkçe Öğretmenliği ve Sınıf Öğretmenliği bölümleri ile aralarında $\mathrm{p}<.05$ düzeyinde anlamlı farklılık oluşmuştur.

\section{Çalışmanın Dördüncü Alt Problemine Yönelik Elde Edilen Bulgular}

Çalışmanın dördüncü alt problemi “Öğretmen adaylarının genel ağırlıklı not ortalamalarına (GANO) göre örtük programdan kaynaklanan stres algıları anlamlı farklılık göstermekte midir?" biçiminde olup, ölçekte yer alan alt boyutlara ve ölçeğin tamamına yönelik veri seti aracılığ 1 ile elde edilen bulgular Tablo 9'da gösterildiği biçimdedir.

Tablo 9. Öğretmen Adaylarının GANO Puanlarına Göre Örtük Programdan Kaynaklanan Stres Algıları Arasında Anlamlı Farklılı̆̆ 1 Gösteren Mann Whitney U Analizi

\begin{tabular}{lrrrrrr}
\hline Boyut & GANO & $\mathbf{n}$ & Sira ortalaması & Sira toplamı & $\mathbf{U}$ & $\mathbf{p}$ \\
\hline Öğrenci & $2,00-2,99$ & 194 & 177,19 & 34375,50 & 15460.50 & .304 \\
& $3,00-4,00$ & 170 & 188,56 & 32054,50 & & \\
\multirow{2}{*}{ Öğretmen } & $2,00-2,99$ & 194 & 178,93 & 34712,00 & 15797.00 & .489 \\
& $3,00-4,00$ & 170 & 186,58 & 31718,00 & & \\
Tamamı & $2,00-2,99$ & 194 & 177,77 & 34487,00 & 15572.00 & .359 \\
& $3,00-4,00$ & 170 & 187,90 & 31943,00 & & \\
\hline
\end{tabular}

Öğretmenadaylarının örtük program kaynaklı stres algılarına yönelik her bir boyut ve tamamı için alınan puanlar GANO puan aralıklarına bağlı olarak herhangi bir anlamlı farklılık göstermemektedir ( $p>.05)$.

\section{Tartışma, Sonuç ve Öneriler}

$\mathrm{Bu}$ bölümde çalışmada ele alınan öğretmen adaylarının örtük program kaynaklı stres algılarının örgüt kültürünün işlevleri kapsamında değerlendirilmesi yapılmış, elde edilen bulgular yoluyla ulaşılan çıkarımlara ilgili alanyazını gözetilerek ve alt problemler bazında ayrı ayrı ele alınarak değinilmiş ve bu çıkarımlar doğrultusunda uygulayıcı ve araştırmacılara öneriler sunulmuştur.

Çalışmanın ilk alt problemi olan öğretmen adaylarının örtük program kaynaklı stres algılarına yönelik betimsel istatistiklere bakıldığında öğretim elemanı boyutunda ve bunun yansıması olarak elde edilen verilerin bütününde stres algısının yüksek çıktığı görülmüştür. $\mathrm{Bu}$ durumu öğretim elemanlarının tutum ve davranışları önemli ölçüde etkilemektedir. Öğretim elemanlarının resmi programları yürütme sürecinde gerçekleştirdikleri örtük program uygulamaları zamanla örgüt kültürü haline gelmiştir denilebilir. Norman (1991) moral ve güdüleme sağlaması bakımından örgüt kültürünün önemli işlevleri olduğunu 
belirtmiştir. Öğretmen boyutuyla ilgili olarak öğretmen adayları üzerinde özellikle stres yaratan durumlar; öğretim elemanlarının öğrenciler arasında eşitliği zedelemesi, kaba ve sert davranışlar sergilemesi, sınıfın önünde alay etmesi vb. olarak sıralanabilir. Bu durum arzu edilen olumlu okul kültürüne zarar verici bir etkiye sahiptir. Aynı zamanda öğretmen adaylarının moral ve güdülenmesine de bir katkı sağlamamaktadır. Okulların olumlu okul kültürü ve olumlu ilişkiler kurması için bazı hedefler belirlemesi önemlidir (Letizia, 2017). Belli bir kültürel yapıda verilen hizmetlerin yürütülebilmesi için kurumlardan beklenen üyelerine bu yönde eğitimler vermesidir (Lebor, 2017). Çalışma kapsamında elde edilen bulgulardan yola çıkarak örgüt kültürünün önemli bir işlevi olan moral ve güdülemeyi düşürücü yöndeki örtük program uygulamalarından vazgeçecek şekilde örgüt üyelerine eğitim vermek ve bu tip uygulamaların örgüte verdiği zarara yönelik farkındalık yaratacak seminerler düzenlemek faydalı olacaktır.

Öğrenci boyutuyla ilgili olarak çalışmanın ilk alt probleminde öğretmen adaylarını belirgin bir biçimde strese sokan durumlar; izinsiz eşya kullanımı, lakap takılması, konuşmaların kaba olması, dedikodu yapılması vb. durumlar olarak sıralanmıştır. Resmi programın ötesinde bireyleri yaşama hazırlarken öğretmenlerin uygulayageldikleri örtük programdan beklenen, örgüt üyelerine hem mesleki anlamda hem de toplumsal ilişkiler anlamında olumlu katkı sağlamasıdır. Ginsburg ve Clift (1990) tarafından öğretmen eğitimine yönelik olarak üç kategoride ele alınan örtük program; toplum ve toplumla ilişkiler başlığında bu yönden eleştirilmiş, sadece var olan mevcut olumlu yönlerin mesaj olarak iletildiği, olumsuz yönler üzerinde pek durulmadığı belirtmiştir. Bu durum örgüt kültürünün işlevlerinden biri olarak görülen sosyalleşme süreciyle de yakın ilişkilidir. Üniversiteden yeni mezun olan bir öğretmen adayının yeni bir hayata başlaması, yeni işine alışması ve mensubu olacağa örgüte uyum sağlaması zor bir geçiş dönemi olarak görülebilir (Çalık, 2006). Bu bağlamda eğitim fakültelerinde öğretim elemanlarının ilk günden itibaren öğrencilerini meslektaş olarak görerek, öğretmenlerden beklenen tutum ve davranışları onlara uyguladıkları örtük programlar aracılığı ile aşılaması öğretmen adaylarına hem mesleki hem de vatandaşlık anlamında önemli katkı sağlayacaktır. Örgüt kültürünün önemli bir işlevi olan sosyalleşme süreciyle ilgili fonksiyonalist ve diyalektik bakış açıları mevcuttur. Öğretmen adaylarının bu anlamda sosyalleşmesine katkı sağlanırken onları sürecin pasif nesnesi olarak gören ve onları topluma uyduran fonksiyonalist yaklaşım yerine, onları yaratıcı ve çözüm üretici bireyler olarak yetiştiren diyalektik yaklaşımın tercih edilmesi ve bu yönde bir örgüt kültürünün oluşturulması daha doğru olacaktır denilebilir.

Çalışmanın ikinci alt probleminde öğretmen adaylarının örtük program kaynaklı stres algılarının cinsiyete göre farklılık gösterip göstermediği ele alınmış ve kadın öğretmen adayları lehine stres algısının daha üst düzeyde olduğu sonucuna ulaşılmıştır. Benzer şekilde Donmuş, Akpınar ve Eroğlu (2017) ve Ekici (2006) araştırmalarında kadın öğretmen adaylarının erkek öğretmen adaylarına nazaran daha fazla başa çıkma çabası sergilediğini belirtmiştir. Bu durumla bağlantılı olarak kadın öğretmen adayları lehine stres algısının artması söz konusudur. Cin (2017) ise araştırmasında cinsiyete göre eğitimde yaşanan zorlukları ele almış, toplumsal cinsiyetin özellikle eğitim ve okulla ilgili olarak dünyada geniş bir eşitsizlik yelpazesini etkilediğini belirtmiştir. Ayrıca Keskin ve Orgun'un (2006) araştırmasında kadın öğretmen adaylarının daha duygu yönelimli olduğunu işaret etmiş olması, çalışmamızın bu yöndeki sonuçları ile örtüşmektedir. Eğitim ortamlarının ve eğitimle ilgili örgütlerin nezih ortamlar olması gereğinden hareketle bu ortamların sahip olduğu örgüt kültürünün önemli bir işlevinin de örgütsel iklimin belirleyicisi olduğunu söylemek 
mümkündür. Örgütsel iklimin hayata geçirilmesinde eğitim örgütlerinde var olan örtük program uygulamalarının önemli bir etkisi vardır. Bu anlamda ilgili kurumlarda uygulanan örtük programların cinsiyet bakımından öğretmen adaylarını güçlendirecek ve onları atılacakları yaşantıya hazırlayacak yönde olması önemlidir.

Çalışmanın üçüncü alt probleminde öğretmen adaylarının bölümlerine göre stres algıları arasında anlamlı fark olup olmadığı araştırılmış, öğrenci boyutunda herhangi bir anlamlı farklılık olmadığı, ancak öğretmen boyutunda ve dolayısıyla ölçme aracı ile toplanan verilerin tamamında bölümlere göre anlamlı farklılığın olduğu tespit edilmiştir. Bölümlere göre öğrenci boyutunda anlamlı bir farkın görülmemiş olmasından öğretmen adaylarının fakülte bazında benzer kültüre sahip oldukları anlamı çıkarılabilir. Wren (1999) örtük programın ekseriyetle kurumda bulunan tüm bireyleri etkileme gücüne sahip olduğunu belirtmektedir. Ancak eğitim fakültelerini örgüt kültürü bakımından bir bütün olarak düşünmekle birlikte içerisinde bulunan her bir bölümü bir alt kültür olarak kabul etmek de gerekmektedir. Örgüt kültürünün bir diğer işlevi de ait olduğu örgüte yönelik bir biçimlendirme aracı olarak görülmesidir. Bu noktada eğitim fakültelerinde yer alan her bir bölümün ayrı bir disiplin olmasından hareketle o bölümlerde izlenen örtük programlarda farklılıkların olması ve bu durumun doğal olarak örtük program kaynaklı stres algılarında farklılık yaratması mümkündür. Özellikle bölümlere göre öğretmen boyutunda böyle bir farklılı̆̆ın çıkmış olması ilgili bölümlerde görev yapan öğretim elemanlarının mensubu oldukları kültürü örtük program aracılığı ile yansitıyor oluşunun bir göstergesidir denilebilir. Araştırmanın yapıldığı fakültede bölümlere göre toplanan verilerin tamamına yönelik alınan puanların sıra ortalaması en düşük değerde olan bir bölüm ile en yüksek değerde olan iki bölüm arasında anlamlı farklılık görülmüştür. Bu durum örgüt kültürünün bir örgütsel biçimlendirme aracı olması yönündeki işlevi ile örtüşmektedir. Ancak bu çalışmanın sınırlılıkları düşünüldüğünde elde edilen bulgular, ilgili bölümlerde görülen örtük program kaynaklı stres algılarıyla ilgili ortaya çıkan anlamlı farklılığın açıklanmasını mümkün kılmamıştır. Bu durum daha sonraki araştırmacılar için ilgi çekici bir araştırma konusu olabilir ve bu yönde çalışmalar yapılabilir.

Çalışmanın dördüncü alt problemi öğretmen adaylarının GANO puanlarına göre örtük program kaynaklı stres algılarında anlamlı bir farklılığın olup olmadığının tespitine yönelik oluşturulmuş olup, bu yönde herhangi bir anlamlı farklılık tespit edilememiştir. Örgüt kültürünün diğer bir işlevinin de örgüt içinde istikrar göstergesi olduğundan hareketle akademik anlamda araştırmanın yapıldığ fakültede belli bir istikrarın oturtulmuş olduğu ve bu durumun uygulanan örtük program aracılığı ile sağlandığ söylenebilir. Gordon, Beatrice ve Aundra (2005) örtük program aracılığı ile kurumların yıllar içinde kalıplaşan ve o kuruma ait bir kültürel yapının oluştuğunun altını çizmektedir. Aynı istikrarın örgüt kültürünün diğer bir işlevi olan örgütsel değişimin belirleyicisi olması yönünde de işlevsel hale getirilebileceğinden bahsedilebilir ve böylesi örgüt kültürüne sahip olan kurumlar için akademik başarıyı artırıcı çalışmaların uygulanacak örtük programlar aracılığı ile etkili sonuçlar vermesinin mümkün olduğu ilgili kurum yöneticileri tarafından gözetilebilir. Örgüt paydaşlarının örgüt amaçları çerçevesinde sağlayacakları belli uzlaşılar, örgüt içerisinde uygulanan örtük programların oluşumuna ve dolayısı ile örgüt kültürüne ve örgütün gelişimine önemli ölçüde katkı sağlayacaktır denilebilir. 


\section{Kaynakça}

Adler, S. (2006). The reflective practitioner and the curriculum of teacher education. journal of education for teaching. International Research and Pedagogy, 17 (2), 139 - 150. Erişim adresi: https://doi.org/10.1080/0260747910170203

Büyüköztürk, Ş., Çakmak, E. K., Akgün, Ö. E., Karadeniz, Ş. ve Demirel, F. (2013). Bilimsel Araştırma Yöntemleri (14. Bask1). Ankara: Pegem Akademi.

Ahola, S. (2000). Hidden Curriculum In Higher Education - Something To Fear For Or Comply To? Paper presented at the Innovations in Higher Education 2000 conference, Helsinki. Erişim adresi: http://ruse.utu.fi/pdfrepo/HCarticle.pdf

Astin, A., W. (1993). What Matters in College? Four Critical Years Revised. San Francisco: Jossey - Bass.

Bergenhenegouwen, G. (1987). Hidden curriculum in the university. Higher Education, 16 (2), $535-543$.

Cin, F. M. (2017). Gender Justice, Education and Equality: Creating Capabilities for Girls' and Women's Development. Cham: Springer.

Çalık, C. (2006). Örgütsel sosyalleşme sürecinde eğitimin değişen rolü ve önemi. Kastamonu Eğitim Dergisi, 14 (1), 1 - 10. http://www.kefdergi.com/pdf/14_1/001-010.pdf

Donmuş, V., Akpınar, B. ve Eroğlu, M. (2017). Öğretmen adaylarının akademik özyeterlikleri ve mesleki kaygıları arasındaki ilişkinin incelenmesi. Mustafa Kemal Üniversitesi Sosyal Bilimler Enstitüsü Dergisi, 14 (37), 1 - 13. http://sbed.mku.edu.tr/article/view/5000179806

Ekici, G. (2006). Meslek lisesi öğretmenlerinin öğretmen öz-yeterlik inançları üzerine bir araştırma. Eurasian Journal of Educational Research, 24, 87 - 96.

Ginsburg, M. ve Clift, R. (1990). The hidden curriculum in teacher education. W. R. Houston, M. Haberman ve J. Sikula (Ed.). Handbook of Research on Teacher Education (450 - 465) içinde. New York: Macmillan.

Gordon,W.E., Beatrice, L., B. and Aundra, S., M. (2005). Supplementary Education: The Hidden Curriculum of High Academic Achievement. Maryland: Rowman and Littlefield Inc.

Karasar, N. (2012). Bilimsel Araştırma Yöntemi ( 24. Baskı) içinde (79). Ankara: Nobel Yayınevi.

Keskin, G., Ü. ve Orgun, F. (2006). Öğrencilerin öz etkililik-yeterlilik düzeyleri ile başa çıma stratejilerinin incelenmesi. Anadolu Psikiyatri Dergisi, 7 (2), 92 - 99.

Korthagen, F., A., J. ve Kessels, J., P., A., M. (1999). Linking theory and practice: changing the pedagogy of teacher education. Journal Educational Reseacher, 28 (4), 4-17. Erişim adresi: https://doi.org/10.3102/0013189X028004004

Lebor, M. (2017). Classroom Behaviour Management in the Post-School Sector: Student and Teacher Perspectives on the Battle Against Being Educated. Cham: Springer.

Letizia, A., J. (2017). Democracy and Social Justice Education in the Information Age. Cham: Springer.

Margolis, E. (2001). Hidden Curriculum in Higher Education. New York: Routledge Margolis. 
Margolis, E. ve Romero, M. (1998). The department is very male, very white, very old, and very conservative: The functioning of hidden curriculum in graduate departments. Harvard Educational Review, 68 (1), 1-32. Erişim adresi: http://dx.doi.org/10.17763/haer.68.1.1q3828348783j851

Nelsen, R, W. (1981). Reading, writing and relationship: Toward overcoming the hidden curriculum of gender, ethnicity and socio - economic class. Interchange, 12 (2 - 3), 229 242. Erişim adresi: https://link.springer.com/content/pdf/10.1007\%2FBF01192117.pdf

Norman, R. (1991). Service Management; Strategy and Leadership in Service Business. New York: John Wiley Ltd.

Rennet-Ariev, P (2008). The hidden curriculum of performance-based teacher education. Teachers College Record, 110 (1), 105-138. Erişim adresi: https://eric.ed.gov/?id=EJ825485

Savcı, M. ve Aysan, F. (2014). Üniversite öğrencilerinde algılanan stres düzeyi ile stresle ile başa çıkma stratejileri arasındaki ilişki. Uluslararası Türk Ĕ̆itim Bilimleri Dergisi, Ekim 2014, 44 - 56. Erişim adresi: https://dergipark.org.tr/download/article-file/406063

Schein, E. H. (1992). Organizational Culture and Leadership. San Fransisco: Jossey - Bass Publishers.

Schein, E. H. (1988). How Culture Forms, Develops and Changes, Gaining Control of the Corporate Culture. London: Jossey - Bass Pub.

Snyder, B. (1971). The Hidden Curriculum. New York: Knopf.

Şahin, B. (2012). Metodoloji. Tanrıöğen, A. ( Ed.), Bilimsel Araştırma Yöntemleri (3. Baskı) içinde (109 - 130). Ankara: Anı Yayıncilık.

Şimşek, A. (2012). Araştırma modelleri. Şimşek, A. (Ed.), Sosyal Bilimlerde Araştırma Yöntemleri (1. Baskı) içinde (80 - 107). Eskişehir: Anadolu Üniversitesi Yayınları.

Wren, D, J. (1999) School culture: exploring the hidden curriculum. Adolescence, 34 (135), 593 - 596. https://eric.ed.gov/?id=EJ610958

Yangın, S. ve Dindar, H. (2010). İlköğretim okullarında örtük programın varlığına ilişkin bir araştırma (Türkiye: Siirt ili örneği). Gazi Eğitim Fakültesi Dergisi, 30 (3), 1017 - 1038. Erişim adresi: http://gefad.gazi.edu.tr/article/view/5000078492/5000072713

Yıldırım, F., ve Gürol, M. (2017). İlköğretim öğrencilerinin örtük programdan kaynaklanan stres algılarının belirlenmesi ölçeği. Uluslararası Eğitim Bilimleri Dergisi, 4 (12), 26-39. https://dergipark.org.tr/download/article-file/563884

Yüksel, S. (2002). Yükseköğretimde eğitim-öğretim faaliyetleri ve örtük program. Uludă̆ Üniversitesi Eğitim Fakültesi Dergisi, 15 (1), 361-370. Erişim adresi: https://dergipark.org.tr/download/article-file/153211 